\title{
SWITCH1 (SWI1): a novel protein required for the establishment of sister chromatid cohesion and for bivalent formation at meiosis
}

\author{
Raphaël Mercier, ${ }^{2}$ Daniel Vezon, Erika Bullier, Juan C. Motamayor, ${ }^{1}$ Aurélie Sellier, François \\ Lefèvre, Georges Pelletier, and Christine Horlow \\ Station de Génétique et d'Amélioration des Plantes, Institut National de la Recherche Agronomique, Route de Saint-Cyr, \\ 78026 Versailles cedex, France
}

\begin{abstract}
We have characterized a new gene, $S W I 1$, involved in sister chromatid cohesion during both male and female meiosis in Arabidopsis thaliana. A first allele, swi1.1, was obtained as a T-DNA tagged mutant and was described previously as abnormal exclusively in female meiosis. We have isolated a new allele, swi1.2, which is defective for both male and female meiosis. In swi1.2 male meiosis, the classical steps of prophase were not observed, especially because homologs do not synapse. Chromatid arms and centromeres lost their cohesion in a stepwise manner before metaphase I, and 20 chromatids instead of five bivalents were seen at the metaphase plate, which was followed by an aberrant segregation. In contrast, swi1.2 female meiocytes performed a mitotic-like division instead of meiosis, indicating a distinct role for SWI1 or a different effect of the loss of SWI1 function in both processes. The SWI1 gene was cloned; the putative SWI1 protein did not show strong similarity to any known protein. Plants transformed with a SWI1-GFP fusion indicated that SWI1 protein is present in meiocyte nuclei, before meiosis and at a very early stage of prophase. Thus, SWI1 appears to be a novel protein involved in chromatid cohesion establishment and in chromosome structure during meiosis, but with clear differences between male and female meiosis.
\end{abstract}

[Key Words: SWI1; sister chromatid cohesion; synapsis, meiosis; Arabidopsis thaliana]

Received March 19, 2001; revised version accepted May 18, 2001.

The reduction of chromosome number during meiosis is a central event in the sexual life cycle of eukaryotes. Two rounds of chromosome segregation following a single DNA replication phase lead to a halving of the chromosome number. Sister chromatid cohesion establishment, maintenance, and release have key roles during both meiotic divisions. At metaphase I, sister chromatid cohesion holds homologs together thanks to chiasmata. During anaphase I, sister chromatid cohesion is released along the length of the arm, resolving chiasmata and allowing homologs to separate to opposite poles. Cohesion at the centromere of each univalent is maintained throughout the first division and released at anaphase II, leading to chromatid segregation (Rieder and Cole 1999; Dej and Orr-Weaver 2000; van Heemst and Heyting 2000).

The molecular mechanisms responsible for chromatid

\footnotetext{
${ }^{1}$ Present address: CIRAD-AGETROP BP 5035, 34032 Montpellier cedex, France.

${ }^{2}$ Corresponding author.

E-MAIL rmercier@versailles.inra.fr; FAX 33-1-30-83-33-19.

Article and publication are at http://www.genesdev.org/cgi/doi/10.1101/ $\operatorname{gad} .203201$.
}

cohesion and its two-step dissolution during meiosis are not yet fully understood, especially in higher eukaryotes. In Saccharomyces cerevisiae, a protein complex composed of at least four proteins, called cohesins, plays a central role during both mitosis and meiosis (Nasmyth 1999). Three cohesin subunits are common to mitosis and meiosis (Scc3, Smc1, and Smc3). The fourth protein exists in two versions: Rec8, which is meiosis specific, and Scc1, its mitotic version that is also present at lower level at meiosis. (Klein et al. 1999; Stoop-Myer and Amon 1999). In S. cerevisiae, mutations in Rec8 or Smc3 cause premature sister chromatid separation and random segregation at meiosis I. Thus, Rec8 and Smc3 are required for both arm and centromere cohesion in this organism. Absence of Rec8 in Schizosaccharomyces pombe leads to loss of chromatid arm cohesion before anaphase I and to an equational segregation pattern at meiosis (Molnar et al. 1995; Watanabe and Nurse 1999). In both yeasts, Rec8 is present as punctuate foci on chromosomes at early prophase and is associated with centromere and chromatid arms from pachytene to the onset of anaphase I when Rec8 staining is lost along chromatid arms, but it persists at the centromere until 
anaphase II (Klein et al. 1999; Watanabe and Nurse 1999). Similar complexes have been identified in several higher eukaryotes, indicating that the mechanism of sister chromatid cohesion may be conserved throughout kingdoms (Losada et al. 1998, 2000; Nasmyth et al. 2000; van Heemst and Heyting 2000). Moreover, the role of Rec8 for sister chromatid cohesion during meiosis may be a function conserved between species because a mutation in a Rec8 homolog of Arabidopsis thaliana results in aberrant chromosome behavior (Bai et al. 1999; Bhatt et al. 1999) and because human Rec8 homolog is expressed largely only in meiotic cells (Parisi et al. 1999).

Several other proteins playing crucial roles in chromatid cohesion during meiosis have been identified. S. cerevisiae cells lacking Spo13 or Slk19 undergo a single division that is mainly equational (Klapholz and Esposito 1980; Kamieniecki et al. 2000; Zeng and Saunders 2000). Rec 8 is lost from the chromatid arms and the centromere during anaphase in spo13 or slk19 mutants, indicating a role for these proteins in delaying Rec8 removal from the centromere (Klein et al. 1999; Kamieniecki et al. 2000). The Sordaria macrospora Spo76 protein is required for cohesion during meiosis because 28 chromosomes instead of seven bivalents are seen on the metaphase plate in the spo76 mutant, indicating complete separation of the sister chromatids (Moreau et al. 1985). The chromosomal localization of Spo76 indicates that it might interact with, or be a component of, the meiotic cohesin complex (van Heemst et al. 1999). The Drosophila MEIS322 protein is required for centromere cohesion during meiosis (Tang et al. 1998). Supporting this assumption, a mutation in this gene leads to precocious separation of sister chromatids in late anaphase I. Furthermore, MEIS322 localizes at centromere from prometaphase I to anaphase II (Kerrebrock et al. 1995; Moore et al. 1998). The Drosophila ORD protein is required for the maintenance of cohesion along the chromosome arms and for continued centromeric cohesion after arm cohesion is released at anaphase I. Strong mutations of $O R D$ cause the separation of sister chromatids before anaphase I (Bickel et al. 1996, 1997). The relationship between these proteins and the cohesin complex during meiosis remains to be elucidated.

The mechanism of sister chromatid cohesion establishment during meiosis remains unknown but starts to be understood for yeast mitosis. In S. cerevisiae, the binding of the cohesin complex to DNA at premitotic $S$ phase requires Scc2 and Scc4 proteins (Ciosk et al. 2000), and the establishment of cohesion needs the Ecol/Ctf7 protein (Skibbens et al. 1999; Toth et al. 1999). The S. pombe Scc2 ortholog Mis4 (Furuya et al. 1998) and the Eco1/Ctf7 homolog Esol are also required for sister chromatid cohesion establishment at mitosis (Tanaka et al. 2000). Nevertheless, the involvement of these genes in meiosis remains to be tested.

To better understand the molecular mechanisms involved in meiosis, a mutagenesis approach has been applied to the model plant $A$. thaliana. We previously described the swi1.1 mutant, which is affected in female meiosis (Motamayor et al. 2000). In this study, we pre- sent the isolation and the characterization of a new allele (swi1.2) affected in sister chromatid cohesion and synapsis during male meiosis. In swi1.2, as in swi1.1, female meiocytes perform a mitotic-like division instead of meiosis. As the swi1.2 mutant defect is different between male and female meiosis, the role of SWI1, or the control mechanisms, must be distinct in these two processes. The cellular localization of the protein, present before and at a very early stage of meiosis, indicates a role for SWI1 in the establishment of meiotic sister chromatid cohesion.

\section{Results}

\section{swil.2 is a sterile mutant}

To identify sterile mutants, $\sim 300$ A. thaliana lines generated by chemical mutagenesis were screened. Seventeen lines were found to be altered in fertility, and among them, seven complementation groups of meiotic mutants were obtained. One of these lines showed complete sterility, with nonelongated siliques (fruits) containing no seed. The mutation was found to be sporophytically expressed, monogenic, and recessive because the phenotype segregation fits a 3:1 fertile/sterile plant ratio (321:121). A complementation test with the previously isolated swi1.1 T-DNA mutant was performed by crossing plants heterozygous for the swi1.2 mutation with male fertile homozygous swi1.1. The $\mathrm{F}_{1}$ progeny segregated with a 1:1 ratio (fertile/sterile, 90/78), indicating that this new mutant was allelic to swi1.1; it was therefore called swi1.2. The swi1.2 mutant did not show any developmental abnormality other than nonelongated siliques.

\section{Molecular characterization of the SWI1 gene}

The previously described swi1.1 mutant was isolated from a T-DNA-mutagenized $A$. thaliana collection. Only one T-DNA has been integrated in swil.1 mutant (Motamayor et al. 2000). A 200-bp fragment flanking the left border of the T-DNA was isolated by inverse-PCR experiment. This fragment was then used to screen an $A$. thaliana genomic DNA library, and a $15-\mathrm{kb}$ DNA fragment that spanned the insertion region was isolated. The $15-\mathrm{kb}$ fragment was sequenced and found to be identical to a part of the chromosome 5 P1 clone MFG13 (accession no. AB025621 BA000015). A 5219-bp SalI/SpeI (equivalent to 4460 to 9679 bp of MFG13) DNA fragment was found to restore the wild-type phenotype when transformed into the swi1.1 and swi1.2 mutants (see Materials and Methods). This result confirmed the allelism between swi1.1 and swi1.2 mutants and identified the SWI1 gene.

The coding region composed of seven exons was defined using RT-PCR experiments (Fig. 1A). The 3' and 5' ends of the transcript were cloned using rapid amplification of cDNA ends (RACE). Three clones were obtained after 3' RACE experiments, defining a 344-bp noncoding sequence after the stop codon. 5' RACE experiments with primer 1 produced five clones, defining a transcrip- 


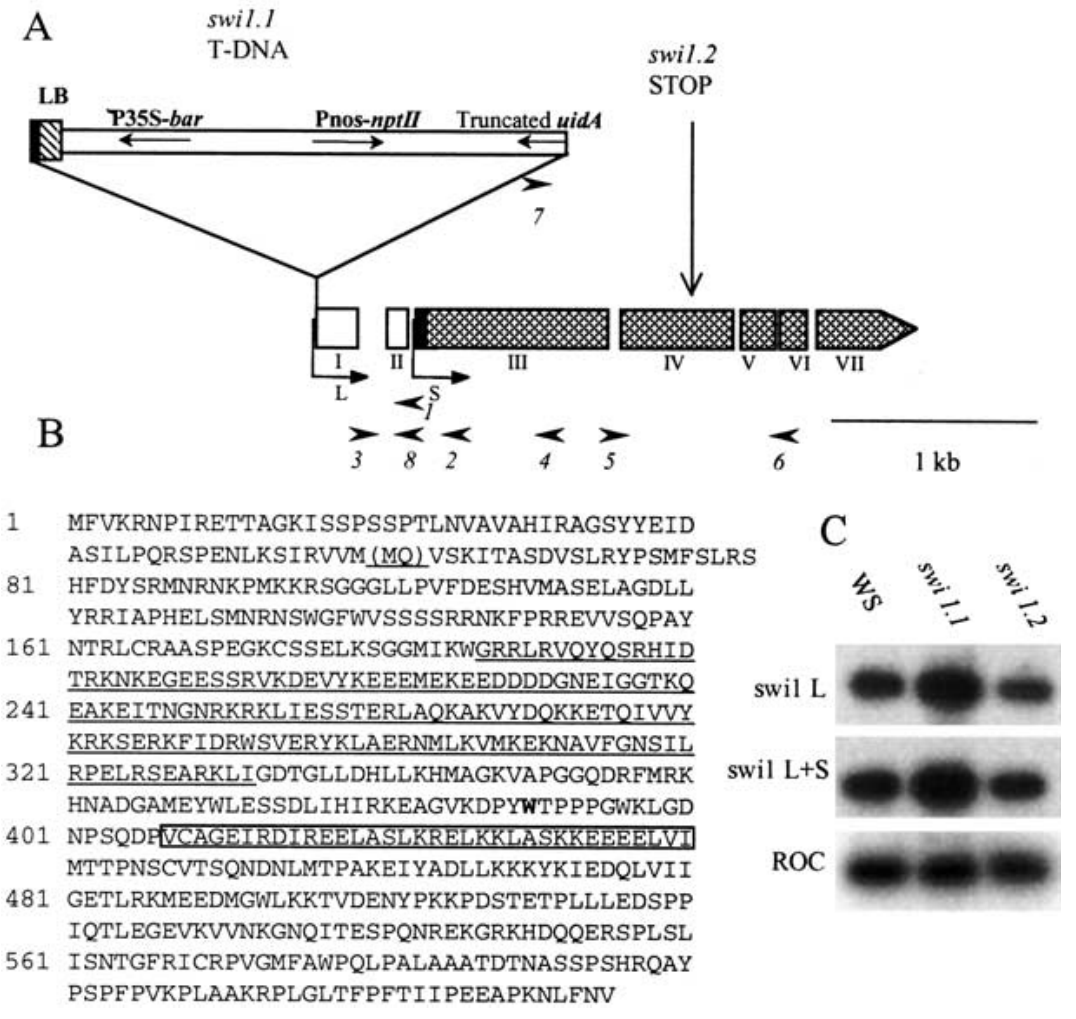

Figure 1. SWI1 gene and molecular characterization of swil mutants. (A) Schematic representation of the SWI1 gene. Bent arrows show the two transcription start points. Exons common to both long (L) and short (S) transcripts are shown in gray. Exons I and II that are present only in the $\mathrm{L}$ transcript are shown in white. The beginning of the short transcript is indicated in black. Horizontal arrows and italicized numbers show the position of primers used in this study. (B) Sequence of the SWI1 protein from the $\mathrm{L}$ transcript. The sequence of the $\mathrm{S}$ transcript begins with the two amino acids shown in brackets. The $\mathrm{W}$ shows the site of the swi1.2 stop mutation. A putative coiledcoil motif is boxed, and the region homologous to SMC proteins is underlined. $(C)$ Expression analysis. RT-PCR products were amplified from flower bud cDNAs using primers specific for the long transcript, the sum of long and short transcripts or the constitutive ROC gene. The expression level was compared between wild type (WS) and the two swil mutants. tion start 93 bp before a putative translation start site. The presence of a stop codon in this $5^{\prime}$ UTR suggested that the cDNA was full length. Interestingly, using primer 2 for 5' RACE, we obtained seven clones, which indicated the position of a second transcription start in intron II, 15 bp 5' of exon III. The exon patterns of the long (L; GenBank AF362001) and short (S; GenBank AF362002) SWI1 transcripts are shown in Figure 1. The two defined transcripts encode 578- and a 635-amino acid (aa) polypeptides, respectively, with a predicted molecular mass of 66 and $72.3 \mathrm{kD}$. A region of the SWI1 protein is predicted to form a coiled-coil (Lupas 1996) from aa 407 to aa 441 (probability 1; for simplicity, the SWI1 L protein is taken as the reference). A potential nuclear localization signal, RKRK (aa 249), was found. Comparison of SWI1 protein with sequences in databases, using BLASTP with filters for areas of low complexity (Altschul et al. 1997), detected no strong similarity with any known proteins. Nevertheless, restrained similarities were found with diverse proteins including a limited similarity (19\% identity on 152 aa, from aa 187 to aa 332) with a region of a SMC (structural maintenance of chromosomes) family protein. This region is highly conserved between human (chromosome-associated polypeptide, bamacam; Shimizu et al. 1998), mouse (SMCD; Darwiche et al. 1999), and Bos taurus (SMC3; Stursberg et al. 1999).

\section{Molecular characterization of the two swil alleles}

Southern blot experiments indicated that the T-DNA inserted in swil.1 mutant was truncated at the right border (data not shown). A 2.5-kb DNA fragment flanking this border of the T-DNA was cloned by the technique of plasmid rescue. This $2.5-\mathrm{kb}$ clone and the 200-bp I-PCR fragment described previously permitted us to define the insertion site. Insertion of the truncated T-DNA occurred 2 bp $3^{\prime}$ of the transcription start of the L transcript (Fig. 1A) and was accompanied by a 20-bp deletion of the genomic DNA (MFG13 8055 to 8036)

The 5219-bp SalI/SpeI swi1.2 genomic DNA fragment was sequenced. A single base substitution was detected, changing the aa 390 sense codon into a stop codon. Moreover, the mutation modified a HinfI restriction site, allowing us to define a CAPS (다eaved amplified polymorphic sequence). Using primers flanking the mutation locus and the HinfI restriction site, we were able to differentiate swi1.2/+ from a +/+ genotype, which are both fertile (data not shown).

Expression of the two transcripts (L and S) was measured in buds of the two mutants and in wild type by RT-PCR, using primers designed at exon junctions to avoid amplification of genomic DNA contamination. The longer transcript was specifically amplified using primers 3 and 4, whereas primers 5 and 6 amplified both $\mathrm{L}$ and $\mathrm{S}$ transcripts. Unfortunately, it was not possible to design primers from the sequence specific to the $S$ transcript. The long transcript and the sum of the two transcripts were detected in the swi1.2 mutant at a similar level to that of wild type (Fig. 1). Therefore, the presence of a stop codon in the middle of the transcript does not affect its transcription level. In the swi1.1 mutant, overexpression was found. This result was unexpected, because the mutation is recessive. The sequencing of a 
cDNA fragment amplified using primers 7 and 8 showed that this expression is the result of a transcriptional fusion between the uidA inverted open reading frame and the SWI1 gene. This fusion was not translated, however, because stop codons are present in the three reading frames before the correct SWI1 translation start. The only way that SWI1 can be synthesized in swi1.1 would be by reinitiation of translation, and this would be expected to produce only low level of the SWI1 protein.

\section{swil.2 is affected in both male and female sporogenesis and gametogenesis}

In plants, meiosis does not directly produce gametes but spores. These spores then undergo haploid mitotic divisions (gametogenesis) to produce the gametophytes, which contain the gametes. Male meiosis and gametogenesis occur in anthers, producing the pollen grain (male gametophyte). The female organ, the pistil, contains ovules. Each mature ovule is composed of three parts: the embryo sac (the female gametophyte); the funicule, which attaches the ovule to the pistil; and the integuments, which progressively surround the developing embryo sac.

In a previous study (Motamayor et al. 2000), the swi1.1 mutant was shown to be affected exclusively in female meiosis and the subsequent gametogenesis. In contrast, swi1.2 was found to be affected in both male and female sexual processes because no seed was produced after self- fertilization or after reciprocal crosses of swi1.2 with wild-type plants. To define the cause of the male and female sterility in the swi1.2 mutant, we examined different developmental stages of anthers and ovules.

Figure 2A shows a wild-type anther containing tetrads of spores, the results of male meiosis. In swi1.2 anthers, male meiocytes have an aberrant shape (Fig. 2C) and subsequently degenerate. In mature wild-type anther, viable pollen grains were stained by the Alexander method (Fig. 2B; Alexander 1969), whereas swi1.2 mature anthers contained no pollen grains (Fig. 2D).

In the female tissues, a meiocyte differentiates in each wild-type ovule (Fig. 2E). Meiosis occurs synchronously with integument initiation (Fig. 2F). Immediately after meiosis, three out of the four spores degenerate (black arrowheads in Fig. 2F). The one remaining, the functional megaspore (white arrowhead in Fig. 2F,G), will proceed through gametogenesis and will generate the mature embryo sac (Fig. $2 \mathrm{H}$ ).

In swi1.2 ovules, early development is similar to that of wild type, with synchronous meiocyte differentiation and integuments initiation. At a postmeiotic developmental stage, (defined by integument development) 25\% of swi1.2 ovules contained an undivided cell and 75\% showed a dyad instead of a tetrad (1562 ovules observed, white arrows in Fig. 2I). At a more advanced developmental stage, ovules contained one $(20 \%)$, two $(25 \%)$, or four/five cells of unequal size $(55 \%$; 648 ovules observed; arrows in Fig. 2K). At the end of ovule development,
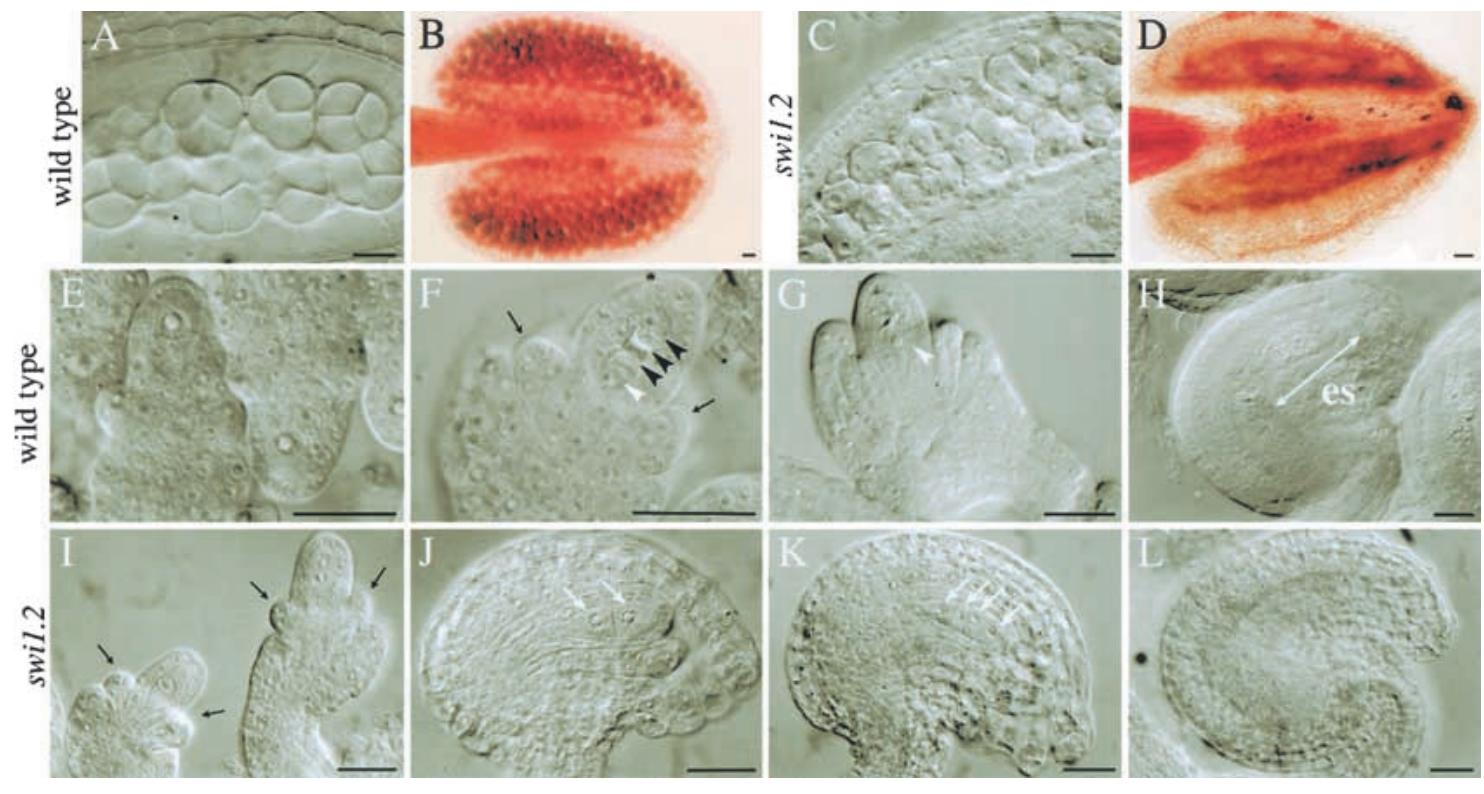

Figure 2. Anther and ovule development in the wild type and swi1.2 mutant. $(A)$ Tetrads of microspores in a wild-type anther. $(B)$ Alexander staining applied to a wild-type mature anther. Viable pollen grains are stained in red. (C) A swi1.2 young anther containing abnormally shaped meiocytes. $(D)$ Swil.2 mature anther void of pollen grain. $(E-H)$ Wild-type ovule development: a female meiocyte differentiates in each ovule $(E)$. Arrowheads in $F$ show the four spores resulting from meiosis. Black arrowheads indicate degenerating spores, and the white arrowhead shows the functional megaspore $(F, G)$. Small arrows show ovule integument initiations. The functional megaspore proceeds to gametogenesis to produce the embryo sac (es; $H)$. ( $I-L)$ Swi1.2 ovule development: Typical images of meiosis and functional megaspore were not visible and were replaced by one or two equilibrated cells $(I)$. One or two rounds of divisions of the meiocyte occur during ovule development instead of meiosis and gametogenesis $(J, K)$. Resulting cells, denoted by white arrows, do not proceed to gametogenesis and degenerate before the end of ovule development $(L)$. Scale bar, $20 \mu M$. 
degenerated cells were observed instead of the embryo sac (Fig. 2L).

The SWI1 gene is required for synapsis and for both chromatid arm and centromere cohesion during male meiosis

To investigate chromosome structure in the swi1.2 mutant, we prepared DAPI-stained spreads of male meiocytes (Fig. 3). In wild type, the 10 chromosomes appeared as threads at leptotene (Fig. 3A), underwent synapsis at zygotene, and were fully synapsed at pachytene (Fig. 3B). The five resulting bivalents condensed (Fig. 3C, arrows show several chiasmata) and arranged at the metaphase plate (Fig. 3D). Bivalents segregated into their univalents at anaphase I, then the univalents arranged at the metaphase II plate (Fig. 3E) and segregated their chromatids to form four sets of five chromatids (Fig. 3F).
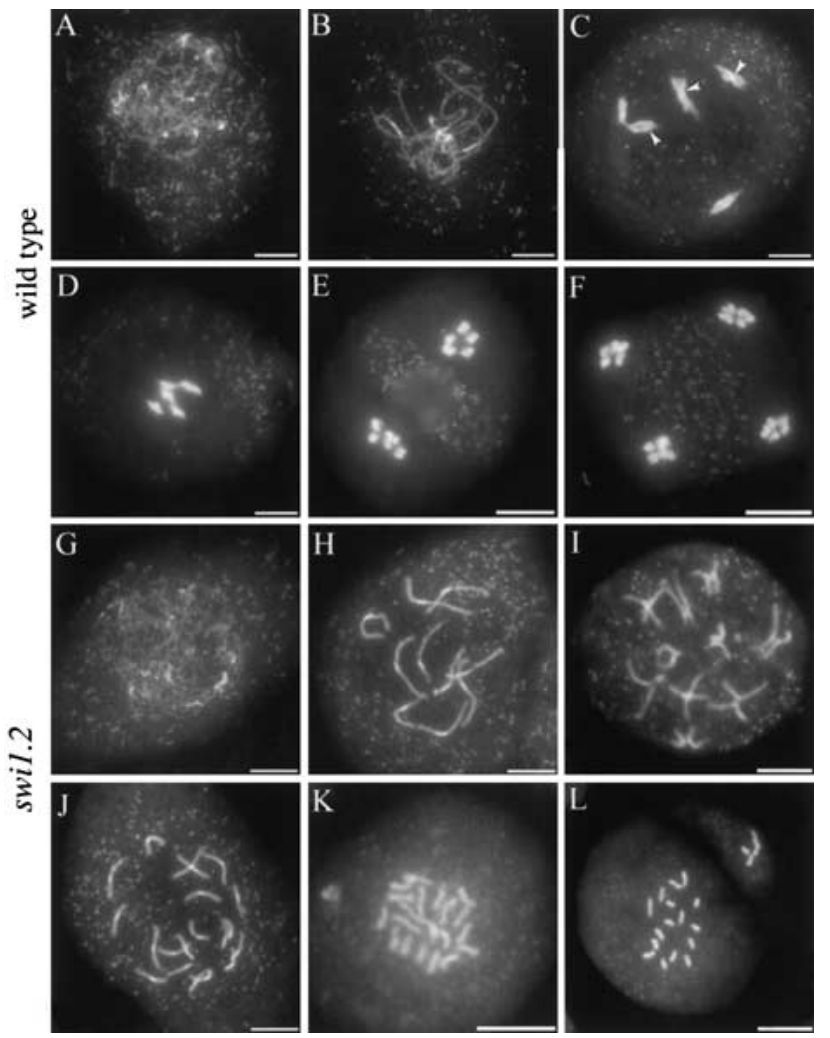

Figure 3. DAPI staining of wild type $(A-F)$ and swi1.2 mutant $(G-L)$ male meiocytes during meiosis. Chromosomes become individualized at leptotene $(A)$ and undergo synapsis, leading to five bivalents at pachytene $(B)$. Chromosomes condense at diakinesis $\left(C_{\text {; }}\right.$ arrows show several chiasmata) and unit at the metaphase plate before the start of anaphase $(D)$. Two sets of five univalents are observed after anaphase I $(E)$; and four sets of chromatids, after anaphase II $(F)$. At the leptotene stage, swi1.2 chromosomes presented a diffuse shape $(G)$. Typical prophase sub-stages did not occur, and 10 univalents appeared $(H)$. Sister chromatid arm cohesion $(I)$ and centromere cohesion were lost $(J)$, leading to 20 separated chromatids at metaphase I $(K)$. Random segregation of these chromatids led to unbalanced daughter cells $(L)$. Scale bar, $5 \mu \mathrm{M}$.
The first detectable abnormality in swi1.2 mutant was the diffuse aspect of leptotene chromosomes (Fig. 3, cf. A with G). Chromosomes condensed but did not undergo leptotene, zygotene, and diakinesis stages. No signs of synapsis (zygotene or pachytene) or chiasmata were detected through $>1000$ cells observed at each stage shown in Figure 3G and 3H. The absence of synapsis led to the presence of 10 univalents instead of 5 bivalents at prometaphase (Fig. 3H). Then, chromatid arms and centromeres lost their cohesion in a stepwise manner before the end of metaphase I, leading first to X-formed univalents (Fig. 3I), indicating that their centromere were still attached, and second to 20 well-separated chromatids. Therefore, only chromatids were seen at metaphase I (Fig. 3J,K), which segregated randomly as shown in Figure $3 \mathrm{~L}$. This phenotype denotes a strong defect in sister chromatid cohesion. The timing of chromosome condensation seems to be affected in swi1.2: Chromosomes are still poorly condensed when chromatid cohesion is lost. Unfortunately, it is very difficult to effectively compare this timing, because no marker of prophase substages is available. However, low condensation nuclei are frequently observed, denoting a general delay in prophase.

To investigate how the segregation of the 20 chromatids occurred, we performed double staining to visualize both DNA and microtubules (Fig. 4). In wild-type meiosis (Fig. 4A-F), microtubules surround the nucleus at diakinesis (Fig. 4A). The spindle is formed in prometaphase, and at anaphase I (Fig. 4B,C) microtubules pull homologs to opposite poles. The two anaphase II spindles (Fig. 4D,E) allow sister chromatids separation, and finally, chromatids decondense (Fig. 4F). Figure 4G shows the 10 chromosomes of a swi1.2 prophase nucleus. At swi1.2 metaphase I/anaphase I, a large spindle surrounded the 20 separated chromatids (Fig. 4H,I). Chromatids were more or less well arranged on the metaphase plate, probably because of small variations in the timing of release of sister chromatid cohesion and spindle formation (cf. with Fig. 3J,K). A subsequent random chromatid segregation produced the unbalanced segregation shown in Figures $3 \mathrm{~L}$ and $4 \mathrm{~J}$. The second division spindles were totally disorganized (Fig. 4K), leading to the formation of a variable number of nuclei, from 1 to 10 , containing unequal amounts of chromatids (Fig. 4L).

\section{In the heterozygous swil.1/swil.2 male meiocytes, both bivalents and univalents are present at the metaphase I plate}

Male meiosis is completely normal in a swi1.1 mutant but is strongly affected in swi1.2. To understand this allelic effect of swi1 mutations on male meiosis, we constructed swi1.1/swi1.2 plants. These plants showed reduced pollen grain production (data not shown), which was an intermediate phenotype compared with the two homozygous mutants.

DAPI-stained spreads of male meiocytes revealed that $50 \%$ of them performed wild-type meiosis (Fig. 5A,B). The remaining meiocytes showed unusual division pat- 


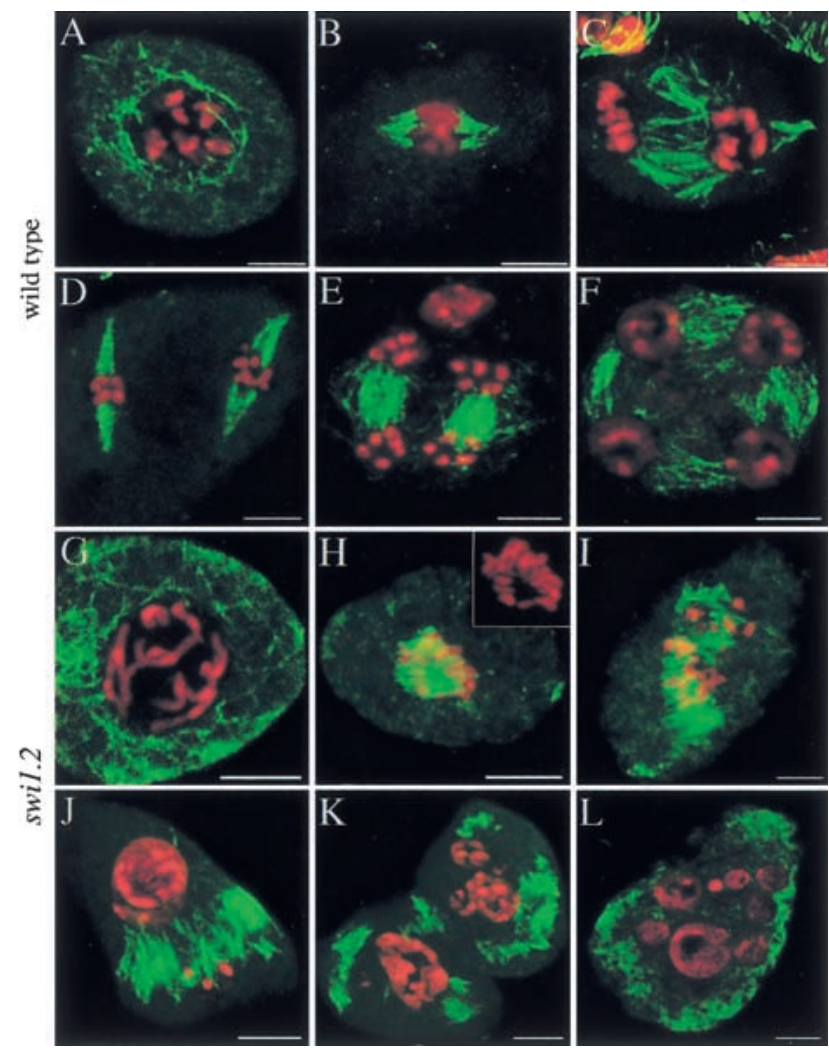

Figure 4. Immunostaining of spindles in wild type $(A-F)$ and swi1.2 male meiocytes $(G-L)$. Chromosomes are stained by propidium iodide (red); and microtubules, by immunolocalization (green). At wild-type prophase $(A)$, tubulin is present throughout the prophase cytoplasm, five bivalents are present in the nucleus. At metaphase I/anaphase I transition $(B)$, bivalents are separated by the spindle into two sets of five univalents $(C)$. At metaphase II/anaphase II transition $(D)$, univalents are separated into four sets of five chromatids by two spindles $(E)$, leading to four nuclei $(F)$. In the swi1.2 mutant, 10 univalents were present in the nucleus, and 20 chromatids were arranged on the metaphase I spindle $(H, I)$. The first chromosome segregation is unbalanced $(J)$, and second division spindles are disorganized $(K)$, leading to a variable number of unbalanced nuclei $(L)$. Scale bar, $5 \mu M$.

tern. At diakinesis and metaphase $\mathrm{I}, \leq 10$ chromosomes could be observed (Fig. 5C-F). These figures are interpreted as being a patchwork of univalents and bivalents. This interpretation was confirmed by observations at early anaphase I. In Figure 5G, at least two segregating bivalents (arrowheads) and univalents could be seen. Anaphase I produces two sets of chromosomes composed of chromatids and univalents (Fig. 5H,I). Note that chromatids are indistinguishable from univalents, but the chromosome number in Figure 6I (17 instead of 20) denotes the presence of three univalents. Two examples of metaphase II are shown in Figure 5J. The cell to the left in Figure 5J was the result of the separation of four bivalents and two univalents at anaphase I. Bivalents and univalents present at metaphase I separated respectively their homologs or their sister chromatids simulta- neously at anaphase I. The four univalents (large arrows) coming from the separation of the four bivalents at anaphase I were able to form a metaphase II plate in each daughter cell (big arrows); two chromatids are unable to join the metaphase plate (small arrows). The cell to the right in Figure 5J could result from the separation of one bivalent and eight univalents because a univalent could be identified because of its alignment on the metaphase plate (large arrow), and eight chromatids are seen in each daughter cell. During the second division, the univalents separated into the two chromatids, but the single chromatids segregated randomly (Fig. 5K,L).

To summarize, in swi1.1/swi1.2 male meiocytes, a patchwork of bivalents and univalents was observed at metaphase I. Bivalents segregated their chromosomes at anaphase I and then their chromatids at anaphase II; whereas univalents segregated their chromatids equally at anaphase I, and these chromatids segregated randomly at anaphase II.

Nevertheless, in some cases, the first segregation was
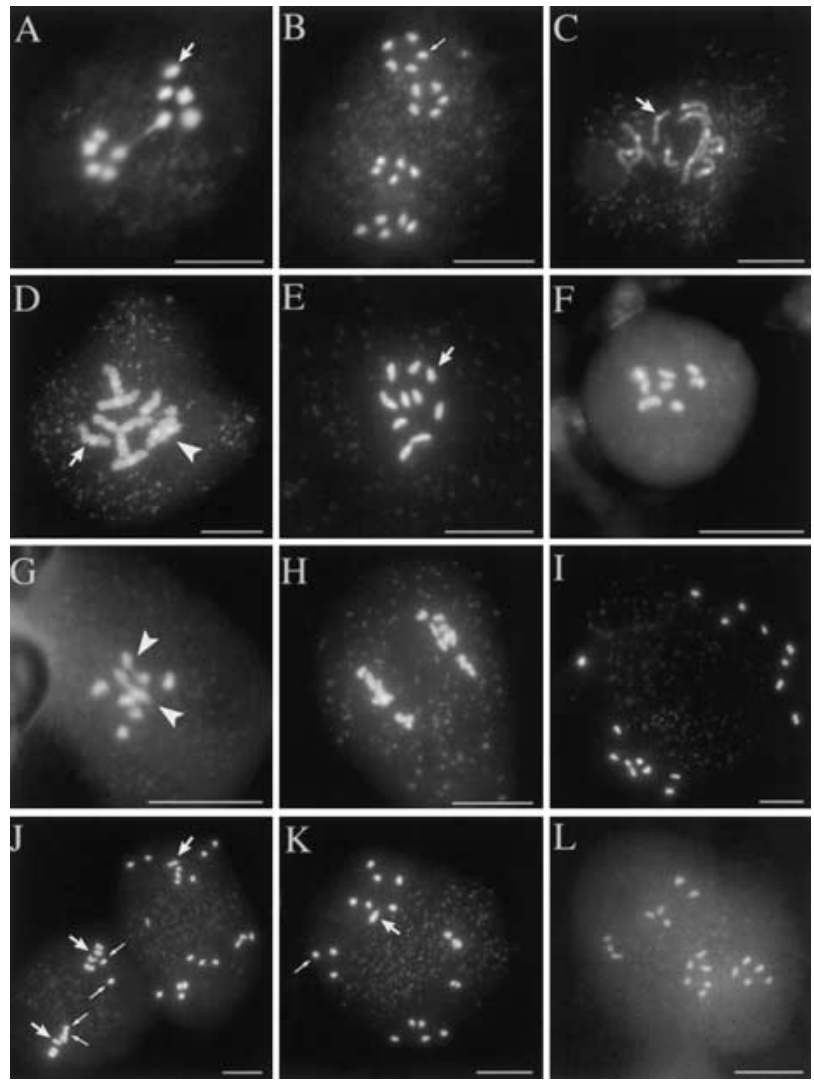

Figure 5. DAPI staining of swi1.1/swi1.2 male meiocytes. $(A, B)$ Fifty percent of the meiocytes performed wild-type meiosis with correct chromosome segregation. $(C)$ Ten condensing univalents. $(D)$ Eight univalents and a putative bivalent at diakinesis. (E) Ten univalents at the metaphase plate. $(F)$ Eight chromosomes interpreted as two bivalents and six univalents. (G) Mix of bivalents and univalents at anaphase I. $(H, L)$ End of anaphase I and subsequent stages up to anaphase II. Bivalents are shown by arrowheads, univalents by large arrows, and chromatids by small arrows. Scale bar, $10 \mu \mathrm{M}$. 
unbalanced as shown in Figure 5K. In the upper daughter cell, 11 chromatids, of which two form a univalent, can be counted. Two hypotheses could explain this unequal result. First, a univalent present at metaphase I may have migrated to one pole of the cell without separating its chromatids. Second, this univalent might have separated its chromatids precociously, as in the swi1.2 mutant, and these chromatids then segregated randomly to the same pole of the cell. swil.2 female meiocytes perform a mitotic-like division

Female meiocytes were observed using propidium iodide staining and confocal laser scanning microscopy (Fig. 6). In wild type, five bivalents were observed on the metaphase plate (Fig. 6A) and segregated into two sets of five univalents (Fig. 6B). Univalents separated their chromatids, resulting into four equilibrated cells (Fig. 6C).

At swi1.2 prometaphase, 10 univalents were observed
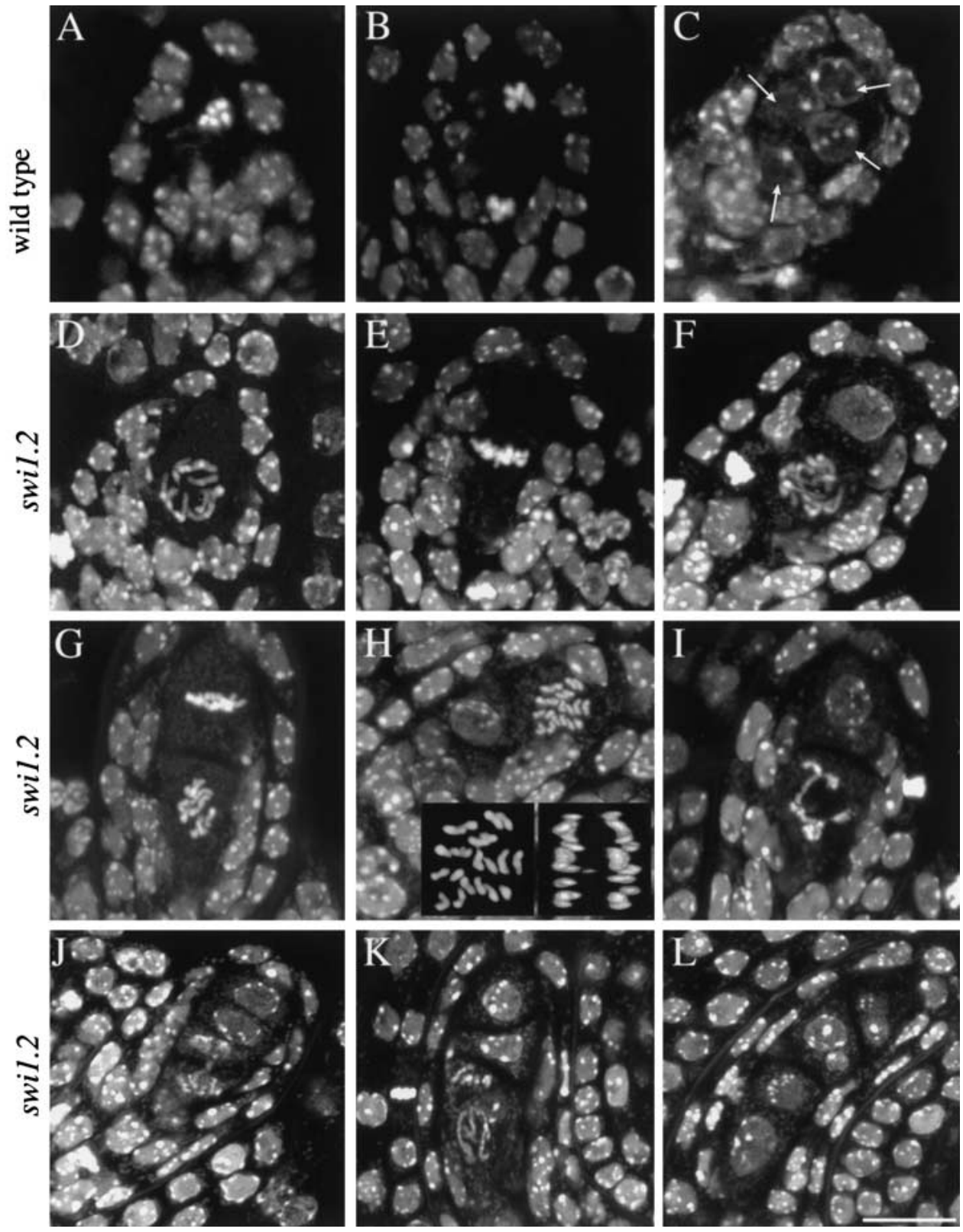

Figure 6. Propidium iodide staining of wild type $(A-C)$ and swi1.2 $(D-L)$ developing ovules at meiosis. $(A)$ Five bivalents at prometaphase. $(B)$ End of anaphase I. $(C)$ Four spores (arrows) resulting from meiosis. $(D)$ Ten univalents at prometaphase. $(E)$ Meiocyte showing a well-organized metaphase plate. $(F)$ Daughter cells, one at interphase and one showing 10 condensing chromosomes. $(G)$ Daughter cells, the upper at metaphase and the lower at prometaphase. (H) Anaphase in a daughter cell, showing 20 chromatids; the threedimensional reconstruction shows two perpendicular planes of the same cell. Each chromatid of univalents segregated to opposite poles. The second cell is at interphase. $(I-K)$ Aberrant metaphase and segregation in daughter cell. $(L)$ Results of meiocyte divisions at an advanced developmental stage of the ovule. Scale bar, $10 \mu \mathrm{M}$. 
(Fig. 6D). These univalents were always observed aligned on an well-organized metaphase plate (Fig. 6E). Meiocytes then performed an equilibrated division (Fig. 6F,G). In 12 daughter cells observed at the same stage, unequilibrated segregation was never seen. Despite the limitation of the resolution of this technique, each of them seems to contain 10 chromosomes. We concluded that this division is a mitotic-like division, but we cannot rule out that this segregation can sometimes be imperfectly equational (e.g., 11 and 9 chromosomes). These data are in agreement with the equilibrated dyads shown in Figure 2I and J. These daughter cells then entered interphase (upper cell in Fig. 6F) and performed a second division. Two different scenarios were then observed. Either the daughter cells proceeded to a complete, including S phase, second mitosis-like division (60\% of 12 cells that can be clearly defined as one of the two classes): 10 univalents regrouped on a metaphase plate (Fig. 6G) and performed a perfect separation of sister chromatids, as it is clearly seen in Figure $6 \mathrm{H}$ and on the corresponding three-dimensional reconstructions. Alternatively, the daughter cell performed an aberrant second division $(40 \%)$. Chromosomes did not unit on a clear metaphase plate (Fig. 6I), and segregation was unequal (Fig. 6J,K). It is possible that in this subset of cells, imperfectly equilibrated segregation could have occurred during the first division, leading to an aberrant second division. The result of these divisions was a variable number of daughter cells with variable size (Fig. 6L). The defects in male and female meiosis induced by swi1.2 mutation were therefore clearly different.

SWI1-GFP protein is localized in meiocyte nuclei just before meiosis and during early prophase

The cytological localization of SWI1 was determined using a green fluorescent protein (GFP)-tagged version of the protein. The construct, when introduced into swi1.1 mutant, restored the fertile phenotype. GFP staining was exclusively detected in female and male meiocyte nuclei, in fresh (Fig. 7A,B) or fixed tissues (Fig. 7C-F).

Figure $7 \mathrm{~A}$ and $\mathrm{B}$ shows an ovule and an anther at the developmental stage of meiosis (red color is the self-fluorescence of chlorophytic tissues). GFP was detected in the nuclei of meiocytes exclusively at this stage. Figure 7C-F shows isolated propidium iodide stained male meiocytes. The red color indicated the stained DNA, which includes genomic, plastidial, and mitochondrial DNA. SWI1-GFP protein was present in the nuclei of premeiotic meiocytes (Fig. 7C). These nuclei, distinguishable by the presence of diffuse chromatin and a central nucleolus, may correspond to meiotic $\mathrm{G}_{1}, \mathrm{~S}$, or $\mathrm{G}_{2}$ phases. Later, in very early leptotene, the GFP staining colocalized with genomic DNA (Fig. 7D, see arrows), indicating that SW11 is a chromosomal-associated protein. Note that the GFP signal did not colocalize with cytoplasmic DNA. GFP staining was absent when chromosomes became individually distinguishable at leptotene (Fig. 7E,F) and was undetectable later in meiosis.
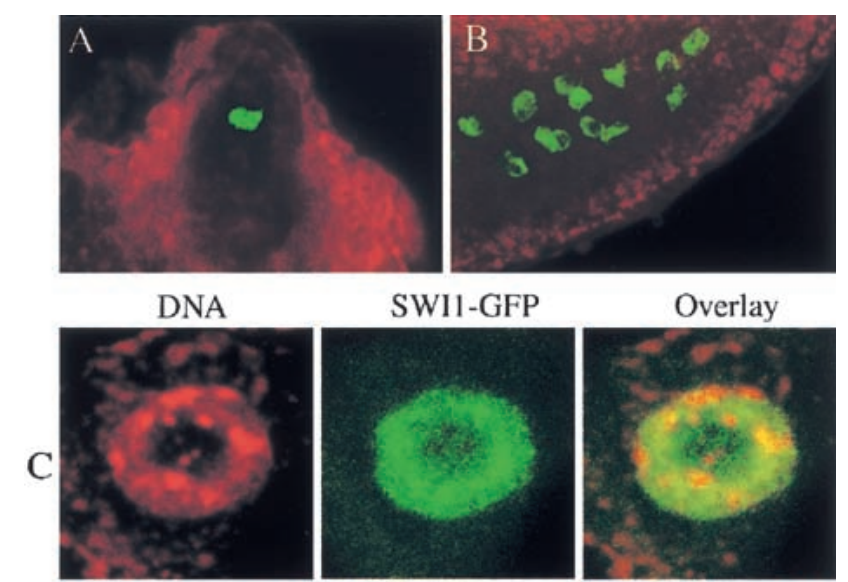

Overlay
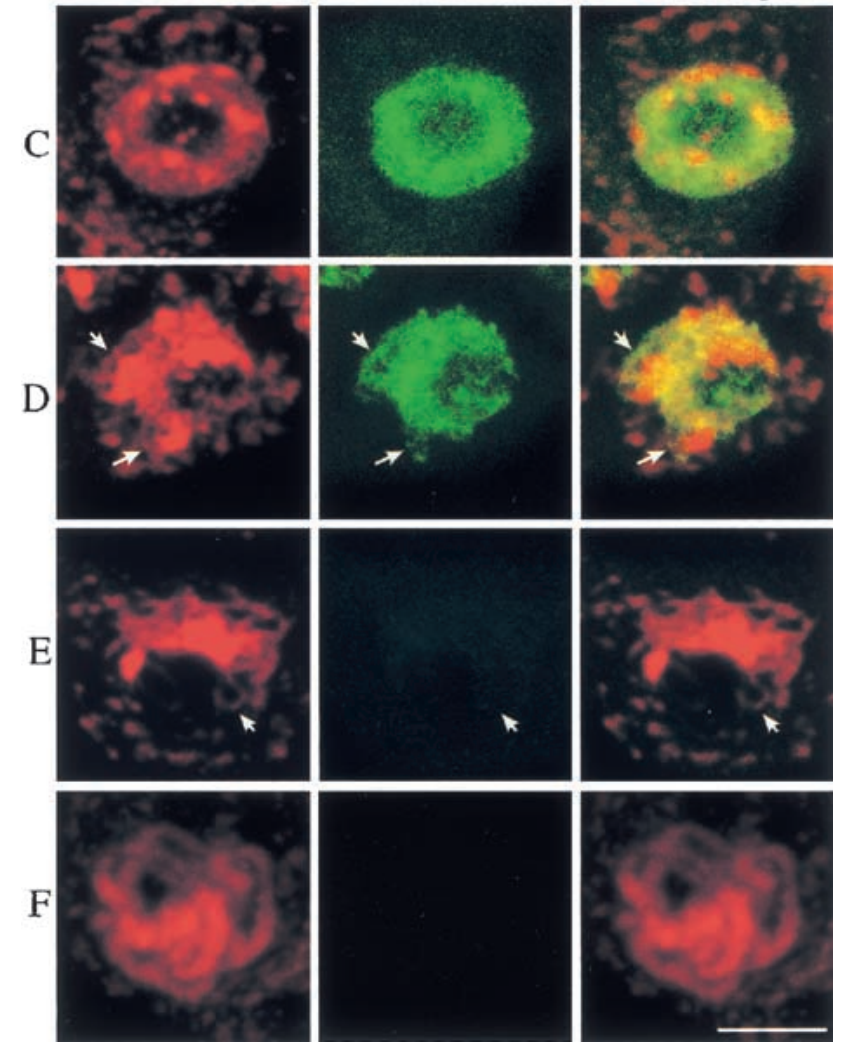

Figure 7. SWI1-GFP localization during meiosis. Fresh ovule $(A)$ and anther $(B)$. SWI1-GFP fusion is visible in green; chlorophyllic tissues show self-fluorescence in red. SWI1-GFP is visible in nucleus of female $(A)$ and male $(B)$ meiocytes. $(C-F)$ Isolated male meiocytes are stained by propidium iodide. Red signal shows genomic, plastidial, and mitochondrial DNA. SWI1GFP is visible in green. Arrows show colocalization of DNA and SWI1-GFP in $D$ and GFP signal disappearance in $E$. Scale bar, 5 $\mu \mathrm{M}$.

\section{Discussion}

SWI1 is involved in chromatid cohesion establishment at meiosis

The major phenotype observed during male meiosis in the swi1.2 mutant is the release of chromatid arms and centromere cohesion before metaphase I. The fusion protein SWI1-GFP is only detected, however, in association with chromosomes, at premeiotic interphase and at very early prophase. SWI1 cannot therefore be a component of the molecular glue that sticks sister chromatids together but probably has a function upstream. However, as swi1.2 chromatids did not fall apart immediately after S phase, SWI1 independent factors are probably required to 
promote this transient initial cohesion. This could be either a protein-mediated system or a topological reason such as DNA intertwining (catenation) resulting from replication, as indicated by mitotic chromosome segregation defect observed in the topoisomerase II mutant top2 of S. cerevisiae (DiNardo et al. 1984). Taking into account the early disappearance of the SWI1 protein, we propose that SWI1 activity is required to establish the system that promotes cohesion between chromatids during the whole of prophase, but not for its maintenance.

Watanabe et al. (2001) showed recently that Rec8-dependant sister chromatid cohesion is established during $S$ phase of $S$. pombe meiosis, but little is known about other proteins involved in this process. This mechanism is better understood for yeast mitosis. Uhlmann and Nasmyth (1998) showed that cohesion is established at premitotic S phase, and several proteins have been identified in yeast that are required for the establishment of cohesion at this stage. First, Scc2 and Scc4 (Ciosk et al. 2000) are required for the establishment of sister chromatid cohesion by permitting the association of the cohesin complex with chromatin. Second, Ecol/Ctf7 (Skibbens et al. 1999; Toth et al. 1999) is not required for the binding of cohesins to chromatin but for the establishment of the sister chromatid cohesion just after their synthesis. Third, the recent isolation of a DNA polymerase required for sister chromatid cohesion reinforces the idea of an intimate link between DNA synthesis and cohesion establishment (Wang et al. 2000). None of these proteins is required for the maintenance of sister chromatid cohesion later in mitotic metaphase. The involvement of these proteins at meiosis has not been tested, and no protein that plays a similar function during meiosis has been described. SWI1 is a candidate protein required for the establishment of sister chromatid cohesion and could have a similar role to that of Scc2, Scc4, or Ecol/Ctf7 proteins but would be specific to meiosis. Nevertheless, we cannot exclude the possibilities that a small amount of SW11 protein, undetectable as a GFP fusion, remains after prophase in meiosis and that SWI1 plays a direct role in sister chromatid cohesion throughout meiosis.

\section{Relationship between synapsis and sister chromatid cohesion}

An interesting feature of the swi1.2 male phenotype is the aberrant chromosome structure seen at meiotic prophase. Leptotene chromosomes have a diffuse shape, and the threads characteristic of pachytene synapsed chromosomes were not observed. Numerous studies have suggested that synaptonemal complex (SC) formation and sister chromatid cohesion could be intimately linked. First, in various organisms, mutants affected in meiotic sister chromatid cohesion are also affected in SC formation. The S. cerevisiae smc3 and rec8 mutants do not form either axial element (AE) or SC (Klein et al. 1999). Lack of the $A$. thaliana SYN1 protein that belongs to Rec8 gene family leads to the disappearance of pachytene stage (Bai et al. 1999). The S. cerevisiae red1 and mek1 mutants, which lose chromatid arm cohesion before metaphase I, show absence of AE /SC and full-length $\mathrm{AE} /$ short stretches of SC, respectively (Bailis and Roeder 1998; Rockmill and Roeder 1990, 1991, 1994). In the Sordaria spo76 mutant, AEs are less regular in shape and less dense than in wild type at leptotene. Furthermore, at zygotene/pachytene, most AEs show split segments, although but most of the remaining unsplit fragments show complete synapsis (Moreau et al. 1985; van Heemst et al. 1999). The maize mutants $d y$ and $d s y$ lose arm cohesion before metaphase I and have altered SC (Maguire 1990; Maguire et al. 1991, 1993). Second, some of the cohesive proteins have been shown to localize along AE. Smc3 and Smc1 proteins localize along AEs of rat SC, and Smcl interacts with two rat SC proteins (Eijpe et al. 2000). Yeast Red1 and Mek1 and Sordaria Spo76 protein localize along AE during prophase (Rockmill and Roeder 1990; Bailis and Roeder 1998; van Heemst et al. 1999).

Therefore, it would seem that the cohesin complex and other proteins involved in sister chromatid cohesion are required for AE formation and synapsis. Van Heemst and Heyting (2000) proposed that meiotic intersister axes contain cohesins and provide the bases for AEs. This hypothesis or, more largely, a model in which AE formation is dependent on previous sister chromatid cohesion establishment, is consistent with the swi1.2 phenotype, in which splitting of synapsis could be a consequence of the nonestablishment of cohesion. The inverse (i.e., synapsis required for the maintenance of cohesion) is unlikely to be the case, as two A. thaliana mutants, asy1 and spo11, show a strong defect in synapsis but are not affected in sister chromatid cohesion (Caryl et al. 2000; Grelon et al. 2001).

It would be very interesting to determine if this relationship is dependent on cohesive proteins such as the SYN1 protein, which is probably an $A$. thaliana meiotic cohesin (Bai et al. 1999).

Why are swi1.1, swi1.2, and swi1.2/swi1.1 phenotypes different?

The swi1.1 mutant (Motamayor et al. 2000) and swi1.2 mutant (this study) present a similar female phenotype (mitosis-like division). Nevertheless, the swil.1 mutation is not fully penetrant because swi1.1 plants can produce about $3 \%$ of embryo sacs compared with wild type, whereas swi1.2 fertility is null. These data are consistent with the molecular characterization of swi1 alleles. First, the swi1.1 T-DNA insertion leads to the production of a SWI1 transcript with a longer 5'. Stop codons present in the three reading frames before the SWI1 translation start prevent the production of a fusion protein. Translation of a normal SWI1 protein in swi1.1 probably occurs at a very low level because its phenotype is leaky, this would correspond to a low efficiency of translation initiation. Second, in the swi1.2 mutant, a single base pair substitution changed a sense codon into a stop codon, preventing the production of correct SWI1 protein.

In swi1.1 plants, male meiosis occurs normally, 
whereas swi1.2 meiocytes lose chromatid arm and centromere cohesion before metaphase I. Therefore, in the swi1.1 mutant, the remaining SWI1 activity is sufficient to ensure synapsis and sister chromatid cohesion, whereas these functions are abolished in swi1.2 mutant. Interestingly, heterozygous swi1.1/swi1.2 plants present an intermediate phenotype. Bivalents and univalents present at the metaphase plate segregate their univalents or their chromatids, respectively, to opposite poles. In the same cell, chromosomes seem to proceed simultaneously to first (separation of the univalents of a bivalent) or second (separation of the chromatids of a univalent) meiotic division. In the swi1.1/swi1.2 genotype, the intermediate level of SWI1 activity would appear to be sufficient to ensure, at least, centromeric cohesion but not $100 \%$ bivalent formation, which can be a defect in chromatid arm cohesion or in synapsis itself. These results confirm that SWI1 is required for synapsis and centromeric and chromatid arm cohesion in male meiocytes but centromeric cohesion seems to be less sensitive to a decrease of SWI1 level than other functions.

The phenotype of swi1.1/swi1.2, with univalents present at metaphase I dividing equally, has been already observed in two A. thaliana mutants: asy1 (Ross et al. 1997), which is an homolog of Hop1, a SC axial/lateral element protein in yeast (Caryl et al. 2000); and dsy1 (Ross et al. 1997), the corresponding gene of which has not yet been isolated. This kind of segregation implies that sister kinetochores, the structure that ensures the attachment of chromatid to the spindle, are oriented toward opposite poles of the cell. In contrast, two other mutants, dmc1 (Couteau et al. 1999) and spo11 (Grelon et al. 2001), that are affected in recombination present univalents at metaphase I, but they segregate randomly without separating their sister chromatids, indicating that the two sister kinetochores are directed toward the same pole of the cell. These data indicate that ASY1, DSY1, and SWI1 are involved not only in the structure of bivalents but also in the structure of each univalent, especially with regard to the orientation of sister kinetochores. These two functions seem to be separable in plants because the spo11 mutant is unable to undergo synapsis but has correctly oriented kinetochores at metaphase I (Grelon et al. 2001).

The separation of these two functions has already been shown in budding yeast, where sister kinetochore orientation by Mamlp is independent of sister chromatid cohesion (Toth et al. 2000).

\section{Distinct mechanisms between A. thaliana male and female meiosis}

A remarkable feature in the swi1.2 mutant is the different phenotype observed in male and female meiocytes. In male meiocytes, chromatid arms and centromeres lose their cohesion in a stepwise manner before the end of metaphase I, leading to chaotic segregation of the resulting 20 chromatids. Female meiocytes, however, show 10 univalents on a metaphase plate and proceed to an apparently equational division. The daughter cells are able to proceed to a second cell cycle, which is either a novel mitotic-like division or an aberrant one.

As SWI1 is involved in sister chromatid cohesion during male meiosis, two hypotheses could explain this phenotype during female meiosis. First, a shunting system, dependant on SWI1, exists in female meiocytes, leading to a complete switching from the meiotic program to a mitotic one in absence of SWI1. This shunting system could be effective at $\mathrm{S}$ phase, when sister chromatid cohesion is established. Second, in female meiocytes, the role of SWI1 is the same as that in male meiocytes, but a mechanism independent of SWI1 ensures centromere cohesion in the female. However, SWI1 would be required at least for bivalent formation, probably via sister chromatid arm cohesion, and for sister kinetochore orientation. Therefore, in swi1.2 female meiocytes, centromeric cohesion could promote an equational segregation of sisters (in other words, a mitotic-like division), as in swi1.1/swi1.2 male meiocytes. This hypothesis is consistent with results described by Paliulis and Nicklas (2000), who showed that a univalent placed in a firstdivision spindle by micromanipulation separates its chromatids to opposite poles. This case has already been observed in the $S$. pombe rec8 mutant and in S. cerevisiae spo13 andslk19 mutants, which perform an equational division instead of a reductional one at anaphase I of meiosis (Klapholz and Esposito 1980; Watanabe and Nurse 1999; Kamieniecki et al. 2000; Zeng and Saunders 2000).

\section{Materials and methods}

\section{Plant material}

swi1.2 was isolated from A. thaliana ecotype Columbia (Col-0) seed stocks that were mutagenized by EMS, essentially as described by Chory et al. (1989). The swi1.2 line was backcrossed twice to the wild-type parent.

\section{Isolation of swi1.1 T-DNA flanking sequences}

The left border was isolated using I-PCR (Thomas et al. 1994). Experiments were performed using Sau 3AI restriction enzyme and primers TAG4 $\left(5^{\prime}\right.$-GTACATTGCCGTAGATGAAAGAC T-3') and TAG5 (5'-CTACAAATTGCCTTTTCTTATCGA-3'). The right border sequence was isolated by performing kanamycin rescue according to Bouchez et al. (1996). A 5.4-kb PstI insert was cloned into pResc $38 ; 2.5 \mathrm{~kb}$ of the cloned insert was found to be plant DNA.

An $A$. thaliana genomic DNA library carried by phage $\lambda$ GEM11 (EEC-BRIDGE $A$. thaliana DNA Stock Center, Cologne; Dr. J. Mulligan, Stanford University, CA) was screened by hybridization using the I-PCR fragment as a probe.

\section{Transcription analyses}

Total RNA was prepared from wild type, swi1.1, and swi1.2 prebolting buds using MessageMaker Reagent assembly (Life Technology). Following DNase treatment, $12 \mu \mathrm{g}$ of RNA for each sample was used for cDNA synthesis using Superscript II (Life Technology) according to manufacturer's protocol.

Amplification of the complete SWI1 L transcript was obtained by PCR experiment using primers 5'-GCGTCGA 
CAAAATGTTCGTGAAACGGAATCCG-3' and 5'-CATGCC ATGGCAACGTTGAAGAGATTCTTGGGA-3' .

5' and 3' RACE experiments were performed using Life Technology systems.

Primers specific for SWI1 used for 5' RACE were an exon VI primer (5'-CCAAACACTGCATTCTTCTCCTT-3') followed by an exon III primer (5'-TCTTCTGTAAAGCAAGTCTCCA $\left.-3^{\prime}\right)$. The last primer was either primer 1 (5'-CGGCGATCTCT GAGGAAGAA-3') or primer 2 (5'-CGAAAACAGGAAGAAG ACCA-3'). For 3' RACE, specific primers used were an exon $\mathrm{V}$ primer (5'-TGCGTCAAAGAAGGAAGAGGA-3') followed by a 3' UTR primer (5'-AACTTACAAGCGAGCAGGTATTT-3'). RACE products were cloned into pGEM-T (Promega).

Expression analyses were performed by PCR on calibrated cDNAs. The calibration was performed to obtain equal signals using amplification with primers specific to the constitutive ROC gene, ROC1F (5'-ATGGCGTTCCCTAAGGTATACTTC GACATG-3') and ROC1R (5'-TCCAGATGATGATCCAACC TTCTCGATGGC-3'; Lippuner et al. 1994). Thirty cycles of PCR amplification, followed by Southern blot analyses, were performed. The L transcript was specifically amplified using primers $3\left(5^{\prime}\right.$-CGTCACCGACTTTGAATGTTGC-3') and 4 (5'GTTATCTCCTTTGCCTCTTGTT- $\left.3^{\prime}\right)$. Primers 5 (5'-TAGAT GGTCTGTTGAGAGGTACAAACT- $\left.3^{\prime}\right)$ and 6 (5'-GCAGAT CAGCGTAGATTTCCTTT-3') amplified both L and S transcripts. The transcriptional fusion in swi1.1 was detected using primers $7\left(5^{\prime}\right.$-TCTTCTGTAAAGCAAGTCTCCA-3 $\left.{ }^{\prime}\right)$ and $8\left(5^{\prime}\right.$ GCAGCGTAATGCTCTACACCACGCC-3').

\section{Phenotypic restoration of swil mutants}

Twelve independent homozygous swi1.1 lines carrying the SalI/ SpeI 5219-bp fragment were produced via Agrobacterium-mediated transformation (Bechtold et al. 1993) and showed restored fertility. This fragment also restored the swi1.2 phenotype: In contrast to swi1.1, homozygous swi1.2 plants are completely sterile and cannot be transformed. We transformed the fertile descendants of swi1.2/+ plants with a segregation that is two thirds swi1.2/+ and one third +/+. Using a CAPS marker, two independent transformed lines were shown to have the swi1.2/ swi1.2 or swi1.2/+ genotype and were completely fertile. It is not possible to distinguish between these two genotypes because of the wild-type SWI1 gene introduced by the transformation. If the introduced fragment was not responsible for this fertility, these plants would have to be swi1.2/+, and the fertility/sterility character would segregate in self-fertilized plants with a $3: 1$ ratio. However, this ratio was respectively $117: 2$ and 55:0, which would only be the case if the introduced fragment restored the fertility in swi1.2/swi1.2 plants.

\section{CAPS}

Using primers flanking the mutation locus $\left(5^{\prime}\right.$-TTTTCAGCA GATCAGCCGTAGA-3' and 5'-AACAAGAGGCAAAGGAGA TAAC-3') and HinfI restriction, the wild-type allele produces a 289-bp fragment, whereas the swi1.2 allele produces a 331-bp fragment.

\section{Light microscopy}

Observation of developing ovule by DIC was performed as described by Motamayor et al. (2000). Development of male meiocytes was observed by DIC as was described by Grelon et al. (2001). DAPI staining of male meiotic chromosomes was performed according to the techniques described by Ross et al. (1996).

\section{Tubulin immunolocalization}

Anthers dissected from 0.3- to 0.4-mm buds were stained according to a protocol modified from Peirson et al. (1997) and Bai et al. (1999). To stabilize cytoskeleton, inflorescences were pretreated with $100 \mu \mathrm{M}$ m-maleimidoenzoyl N-hydrosuccinimide ester, $0.05 \%(\mathrm{v} / \mathrm{v})$ Triton $\mathrm{X}-100$ in $50 \mathrm{mM}$ potassium phosphate buffer ( $\mathrm{PPB}$; $\mathrm{pH}$ 8) $30 \mathrm{~min}$ under vacuum. Inflorescences were fixed for $1 \mathrm{~h}$ in PPB, $4 \%(\mathrm{w} / \mathrm{v})$ paraformaldehyde, $5 \mathrm{mM}$ EGTA, $5 \%(\mathrm{v} / \mathrm{v})$ DMSO and washed in buffer. After a first digestion in $\beta$-glucuronidase, anthers were dissected, squashed, and fixed on slide by freezing on dry ice. The released cells were immobilized with a thin layer of $1 \%$ gelatine $(\mathrm{w} / \mathrm{v}), 1 \%$ agarose $(\mathrm{w} / \mathrm{v}), 2.5 \%$ glucose and digested for $30 \mathrm{~min}$ at $37^{\circ} \mathrm{C}$ by $\beta$-glucuronidase in $\mathrm{PPB}, 7 \%(\mathrm{w} / \mathrm{v})$ sucrose, and rinsed in PPB. Cells were subsequently incubated for 30 min with $1 \%$ triton $X-100(w / v)$ in $\mathrm{PPB}$, rinsed in $\mathrm{PPB}$, and incubated overnight at room temperature with $5 \%(\mathrm{v} / \mathrm{v})$ rat anti-tubulin (MAS 077b, Harlan Sera-Lab, Loughborough, England), $0.02 \mathrm{M}$ sodium phosphate buffer (pH 8), $0.3 \mathrm{M} \mathrm{NaCl}, 0.1 \%(\mathrm{w} / \mathrm{v})$ sodium azide, $0.05 \%(\mathrm{v} / \mathrm{v})$ Triton $\mathrm{X}-100,4.5 \mathrm{mg} / \mathrm{mL}$ BSA. After eight rinses with $0.02 \mathrm{M}$ sodium phosphate buffer $\mathrm{pH} 8$, cells were treated for $5 \mathrm{~h}$ with $0.5 \%(\mathrm{v} / \mathrm{v})$ FITC-labeled secondary antibody (labeled goat anti-rat IgG Alexa fluor 488, A-11006; Molecular Probes Europe BV) at $37^{\circ} \mathrm{C}$. Cells were rinsed six times in PPB and stained for $2 \mathrm{~h}$ in $100 \mu \mathrm{M}$ propidium iodide, $10 \mathrm{mM}$ Tris (pH 8), $10 \mathrm{mM} \mathrm{NaCl}, 0.1 \%$ Nondidet P-40, $10 \mu \mathrm{g} / \mathrm{mL}$ RNase A; rinsed in the same buffer without propidium; and mounted in antifade (Prolong, Molecular Probes).

\section{GFP staining}

The cytological localization of SWI1 was determined using a GFP-tagged version of the protein. The 5219-bp SalI/SpeI was mutated by PCR to delete the SWI1 stop codon and to create a NcoI restriction site $\left(5^{\prime}\right.$-GCTCTAGATTTGCTATCGGAATC TGGGG-3' and 5'-CATGCCATGGCAACGTTGAAGAGATT CTTGGGA-3'). The obtained SalI/NcoI fragment was cloned in pCAMBIA 1302 (CAMBIA GPO) to produce the SWI1-GFP translational fusion. The construct was transferred in swi1.1 mutant, and nine independent lines showed restored fertility. Fresh anthers and ovules were mounted for direct observation. To isolate fixed meiocytes and to stain DNA, the tubulin immunolocalization method was used. Three independent SWI1GFP transformants were analyzed.

\section{Confocal microscopy}

Female meiotic chromosomes were observed by propidium iodide staining and confocal microscopy according to Motamayor et al. (2000). The three-dimensional reconstruction shown in Figure $6 \mathrm{E}$ was obtained by treating forty-six $0.2-\mu \mathrm{M}$ sections with the LEICA power three-dimensional program.

Microscopic observation of cells expressing GFP or stained for tubulin immunolocalization were performed using a LEICA TCS-NT confocal laser scanning microscope (Leica Microsystems) with a argon/krypton laser (Omnichrome). GFP or FITC fluorescence was collected through a FITC filters set (BP520/30) using the 488-nm laser beam. Low scan (220 lines/sec) images $(1024 \times 1024$ pixels $)$ were generated using a $63 \times 1.32$ NA PL APO objective. To collect simultaneously GFP/FITC and propidium iodide signals, a reflect short-pass filter (RSP 580) was used to separate the emission beam in two.

\section{Acknowledgments}

We thank M. Grelon and C. Mezard for stimulating discussion and critical comments of the manuscript. We also thank G. 
Jones for advice on meiocyte spread and O. Grandjean for help on confocal microscopy. We are very grateful to D. Zickler and $\mathrm{H}$. North for critical reading of the manuscript.

The publication costs of this article were defrayed in part by payment of page charges. This article must therefore be hereby marked "advertisement" in accordance with 18 USC section 1734 solely to indicate this fact.

\section{References}

Alexander, M.P. 1969. Differential staining of aborted and nonaborted pollen. Stain Technol. 44: 117-122.

Altschul, S.F., Madden, T.L., Schaffer, A.A., Zhang, J., Zhang, Z., Miller, W., and Lipman, D.J. 1997. Gapped BLAST and PSI-BLAST: A new generation of protein database search programs. Nucleic Acids Res. 25: 3389-3402.

Bai, X., Peirson, B.N., Dong, F., Cai, X., Makaroff, C.A., Bai, X.F., Xue, C., and Dong, F.G. 1999. Isolation and characterization of SYN1, a RAD21-like gene essential for meiosis in Arabidopsis. Plant Cell 11: 417-430.

Bailis, J.M. and Roeder, G.S. 1998. Synaptonemal complex morphogenesis and sister-chromatid cohesion require Mek1-dependent phosphorylation of a meiotic chromosomal protein. Genes \& Dev. 12: 3551-3563.

Bechtold, N., Ellis, J., and Pelletier, G. 1993. In planta Agrobacterium mediated gene transfer by infiltration of adult Arabidopsis thaliana plants. C. R. Acad. Sci. Paris 316: 1194 1199.

Bhatt, A.M., Lister, C., Page, T., Fransz, P., Findlay, K., Jones, G.H., Dickinson, H.G., and Dean, C. 1999. The DIF1 gene of Arabidopsis is required for meiotic chromosome segregation and belongs to the REC8/RAD21 cohesin gene family. Plant J. 19: 463-472.

Bickel, S.E., Wyman, D.W., Miyazaki, W.Y., Moore, D.P., and Orr-Weaver, T.L. 1996. Identification of ORD, a Drosophila protein essential for sister chromatid cohesion. EMBO $\mathrm{T}$. 15: 1451-1459.

Bickel, S.E., Wyman, D.W., and Orr-Weaver, T.L. 1997. Mutational analysis of the Drosophila sister-chromatid cohesion protein ORD and its role in the maintenance of centromeric cohesion. Genetics 146: 1319-1331.

Bouchez, D., Vittorioso, P., Courtial, B., and Camilleri, C. 1996. Kanamycin rescue: A simple technique for the recovery of T-DNA flanking sequences. Plant Mol. Biol. Rep. 14: 115123.

Caryl, A.P., Armstrong, S.J., Jones, G.H., and Franklin, F.C. 2000. A homologue of the yeast HOP1 gene is inactivated in the Arabidopsis meiotic mutant asy1. Chromosoma 109: 62-71.

Chory, J., Peto, C., Feinbaum, R., Pratt, L., and Ausubel, F. 1989. Arabidopsis thaliana mutant that develops as a light-grown plant in the absence of light. Cell 58: 991-999.

Ciosk, R., Shirayama, M., Shevchenko, A., Tanaka, T., Toth, A., and Nasmyth, K. 2000. Cohesin's binding to chromosomes depends on a separate complex consisting of Scc2 and Scc4 proteins. Mol. Cell 5: 243-254.

Couteau, F., Belzile, F., Horlow, C., Grandjean, O., Vezon, D., and Doutriaux, M.P. 1999. Random chromosome segregation without meiotic arrest in both male and female meiocytes of a dmc1 mutant of Arabidopsis. Plant Cell 11: 16231634.

Darwiche, N., Freeman, L.A., and Strunnikov, A. 1999. Characterization of the components of the putative mammalian sister chromatid cohesion complex. Gene 233: 39-47.

Dej, K.J. and Orr-Weaver, T.L. 2000. Separation anxiety at the centromere. Trends Cell. Biol. 10: 392-399.
DiNardo, S., Voelkel, K., and Sternglanz, R. 1984. DNA topoisomerase II mutant of Saccharomyces cerevisiae: Topoisomerase II is required for segregation of daughter molecules at the termination of DNA replication. Proc. Natl. Acad. Sci. 81: 2616-2620.

Eijpe, M., Heyting, C., Gross, B., and Jessberger, R. 2000. Association of mammalian SMC1 and SMC3 proteins with meiotic chromosomes and synaptonemal complexes. J. Cell Sci. 113: 673-682.

Furuya, K., Takahashi, K., and Yanagida, M. 1998. Faithful anaphase is ensured by Mis4, a sister chromatid cohesion molecule required in $S$ phase and not destroyed in $G_{1}$ phase. Genes \& Dev. 12: 3408-3418.

Grelon, M., Vezon, D., Gendrot, G., and Pelletier, G. 2001. AtSPO11-1 is necessary for efficient meiotic recombination in plants. $E M B O$ I. 20: 1-13.

Kamieniecki, R.J., Shanks, R.M., and Dawson, D.S. 2000. Slk19p is necessary to prevent separation of sister chromatids in meiosis I. Curr. Biol. 10: 1182-1190.

Kerrebrock, A.W., Moore, D.P., Wu, J.S., and Orr-Weaver, T.L. 1995. Mei-S332, a Drosophila protein required for sisterchromatid cohesion, can localize to meiotic centromere regions. Cell 83: 247-256.

Klapholz, S. and Esposito, R.E. 1980. Recombination and chromosome segregation during the single division meiosis in SPO12-1 and SPO13-1 diploids. Genetics 96: 589-611.

Klein, F., Mahr, P., Galova, M., Buonomo, S.B., Michaelis, C., Nairz, K., and Nasmyth, K. 1999. A central role for cohesins in sister chromatid cohesion, formation of axial elements, and recombination during yeast meiosis. Cell 98: 91-103.

Lippuner, V., Chou, I.T., Scott, S.V., Ettinger, W.F., Theg, S.M., and Gasser, C.S. 1994. Cloning and characterization of chloroplast and cytosolic forms of cyclophilin from Arabidopsis thaliana. J. Biol. Chem. 269: 7863-7868.

Losada, A., Hirano, M., and Hirano, T. 1998. Identification of Xenopus SMC protein complexes required for sister chromatid cohesion. Genes \& Dev. 12: 1986-1997.

Losada, A., Yokochi, T., Kobayashi, R., and Hirano, T. 2000. Identification and characterization of SA/Scc3p subunits in the Xenopus and human cohesin complexes. J. Cell Biol. 150: 405-416.

Lupas, A. 1996. Prediction and analysis of coiled-coil structures. Methods Enzymol. 266: 513-525.

Maguire, M.P. 1990. Sister chromatid cohesiveness: Vital function, obscure mechanism. Biochem. Cell Biol. 68: 12311242.

Maguire, M.P., Paredes, A.M., and Riess, R.W. 1991. The desynaptic mutant of maize as a combined defect of synaptonemal complex and chiasma maintenance. Genome 34: 879-887.

Maguire, M.P., Riess, R.W., and Paredes, A.M. 1993. Evidence from a maize desynaptic mutant points to a probable role of synaptonemal complex central region components in provision for subsequent chiasma maintenance. Genome 36: 797807.

Molnar, M., Bahler, J., Sipiczki, M., and Kohli, J. 1995. The rec8 gene of Schizosaccharomyces pombe is involved in linear element formation, chromosome pairing and sister-chromatid cohesion during meiosis. Genetics 141: 61-73.

Moore, D.P., Page, A.W., Tang, T.T., Kerrebrock, A.W., and OrrWeaver, T.L. 1998. The cohesion protein MEI-S332 localizes to condensed meiotic and mitotic centromeres until sister chromatids separate. J. Cell Biol. 140: 1003-1012.

Moreau, P.J.F., Zickler, D., and Leblon, G. 1985. One class of mutants with disrupted centromere livage and chromosome pairing in Sordaria macrospora. Mol. Gen. Genet. 198: 189197. 
Motamayor, J.C., Vezon, D., Bajon, C., Sauvanet, A., Grandjean, O., Marchand, M., Bechtold, N., Pelletier, G., and Horlow, C. 2000. Switch (swi1), an Arabidopsis thaliana mutant affected in the female meiotic switch. Sex. Plant. Reprod. 12: 209-218.

Nasmyth, K. 1999. Separating sister chromatids. Trends Biochem. Sci. 24: 98-104.

Nasmyth, K., Peters, J.M., and Uhlmann, F. 2000. Splitting the chromosome: Cutting the ties that bind sister chromatids. Science 288: 1379-1385.

Paliulis, L.V. and Nicklas, R.B. 2000. The reduction of chromosome number in meiosis is determined by properties built into the chromosomes. I. Cell Biol. 150: 1223-1232.

Parisi, S., McKay, M.J., Molnar, M., Thompson, M.A., van der Spek, P.J., van Drunen-Schoenmaker, E., Kanaar, R., Lehmann, E., Hoeijmakers, J.H., and Kohli, J. 1999. Rec8p, a meiotic recombination and sister chromatid cohesion phosphoprotein of the Rad21p family conserved from fission yeast to humans. Mol. Cell Biol. 19: 3515-3528.

Peirson, B.N., Bowling, S.E., and Makaroff, C.A. 1997. A defect in synapsis causes male sterility in a T-DNA-tagged Arabidopsis thaliana mutant. Plant J. 11: 659-669.

Rieder, C.L. and Cole, R. 1999. Chromatid cohesion during mitosis: Lessons from meiosis. J. Cell Sci. 112: 2607-2613.

Rockmill, B. and Roeder, G.S. 1990. Meiosis in asynaptic yeast. Genetics 126: 563-574.

. 1991. A meiosis-specific protein kinase homolog required for chromosome synapsis and recombination. Genes \& Dev. 5: 2392-2404.

- 1994. The yeast med1 mutant undergoes both meiotic homolog nondisjunction and precocious separation of sister chromatids. Genetics 136: 65-74.

Ross, K.J., Fransz, P., and Jones, G.H. 1996. A light microscopic atlas of meiosis in Arabidopsis thaliana. Chromosome Res. 4: 507-516.

Ross, K.J., Fransz, P., Armstrong, S.J., Vizir, I., Mulligan, B., Franklin, F.C., and Jones, G.H. 1997. Cytological characterization of four meiotic mutants of Arabidopsis isolated from T-DNA-transformed lines. Chromosome Res. 5: 551-559.

Shimizu, K., Shirataki, H., Honda, T., Minami, S., and Takai, Y. 1998. Complex formation of SMAP/KAP3, a KIF3A/B ATPase motor-associated protein, with a human chromosome-associated polypeptide. J. Biol. Chem. 273: 6591-6594.

Skibbens, R.V., Corson, L.B., Koshland, D., and Hieter, P. 1999. Ctf7p is essential for sister chromatid cohesion and links mitotic chromosome structure to the DNA replication machinery. Genes \& Dev. 13: 307-319.

Stoop-Myer, C. and Amon, A. 1999. Meiosis: Rec8 is the reason for cohesion. Nat. Cell Biol. 1: E125-E127.

Stursberg, S., Riwar, B., and Jessberger, R. 1999. Cloning and characterization of mammalian SMC1 and SMC3 genes and proteins, components of the DNA recombination complexes RC-1. Gene 228: 1-12.

Tanaka, K., Yonekawa, T., Kawasaki, Y., Kai, M., Furuya, K., Iwasaki, M., Murakami, H., Yanagida, M., and Okayama, H. 2000. Fission yeast Esolp is required for establishing sister chromatid cohesion during S phase. Mol. Cell Biol. 20: 3459 3469.

Tang, T.T.L., Bickel, S.E., Young, L.M., and Orr-Weaver, T.L. 1998. Maintenance of sister-chromatid cohesion at the centromere by the Drosophila MEI-S332 protein. Genes \& Dev. 12: 3843-3856.

Thomas, C.M., Jones, D.A., English, J.J., Carroll, B.J., Bennetzen, J.L., Harrison, K., Burbidge, A., Bishop, G.J., and Jones, J.D. 1994. Analysis of the chromosomal distribution of transposon-carrying T-DNAs in tomato using the inverse poly- merase chain reaction. Mol. Gen. Genet. 242: 573-585.

Toth, A., Ciosk, R., Uhlmann, F., Galova, M., Schleiffer, A., and Nasmyth, K. 1999. Yeast cohesin complex requires a conserved protein, Ecolp(Ctf7), to establish cohesion between sister chromatids during DNA replication. Genes \& Dev. 13: $320-333$

Toth, A., Rabitsch, K.P., Galova, M., Schleiffer, A., Buonomo, S.B., and Nasmyth, K. 2000. Functional genomics identifies monopolin: A kinetochore protein required for segregation of homologs during meiosis i. Cell 103: 1155-1168.

Uhlmann, F. and Nasmyth, K. 1998. Cohesion between sister chromatids must be established during DNA replication. Curr. Biol. 8: 1095-1101.

van Heemst, D. and Heyting, C. 2000. Sister chromatid cohesion and recombination in meiosis. Chromosoma 109: 10 26.

van Heemst, D., James, F., Poggeler, S., Berteaux-Lecellier, V., and Zickler, D. 1999. Spo76p is a conserved chromosome morphogenesis protein that links the mitotic and meiotic programs. Cell 98: 261-271.

Wang, Z., Castano, I.B., De Las Penas, A., Adams, C., and Christman, M.F. 2000. Pol kappa: A DNA polymerase required for sister chromatid cohesion. Science 289: 774-779.

Watanabe, Y. and Nurse, P. 1999. Cohesin Rec8 is required for reductional chromosome segregation at meiosis. Nature 400: 461-464

Watanabe, Y., Yokobayashi, S., Yamamoto, M., and Nurse, P. 2001. Pre-meiotic S phase is linked to reductional chromosome segregation and recombination. Nature 409: 359-363.

Zeng, X. and Saunders, W.S. 2000. The saccharomyces cerevisiae centromere protein slk $19 \mathrm{p}$ is required for two successive divisions during meiosis. Genetics 155: 577-587. 


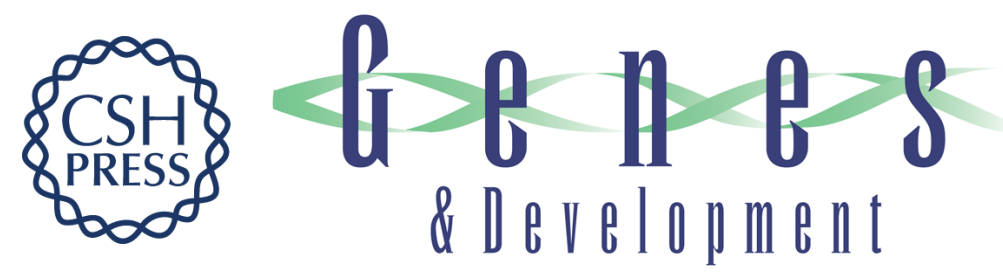

\section{SWITCH1 (SWI1): a novel protein required for the establishment of sister chromatid cohesion and for bivalent formation at meiosis}

Raphaël Mercier, Daniel Vezon, Erika Bullier, et al.

Genes Dev. 2001, 15:

Access the most recent version at doi:10.1101/gad.203201

References This article cites 61 articles, 28 of which can be accessed free at: http://genesdev.cshlp.org/content/15/14/1859.full.html\#ref-list-1

License

Email Alerting

Receive free email alerts when new articles cite this article - sign up in the box at the top Service right corner of the article or click here.

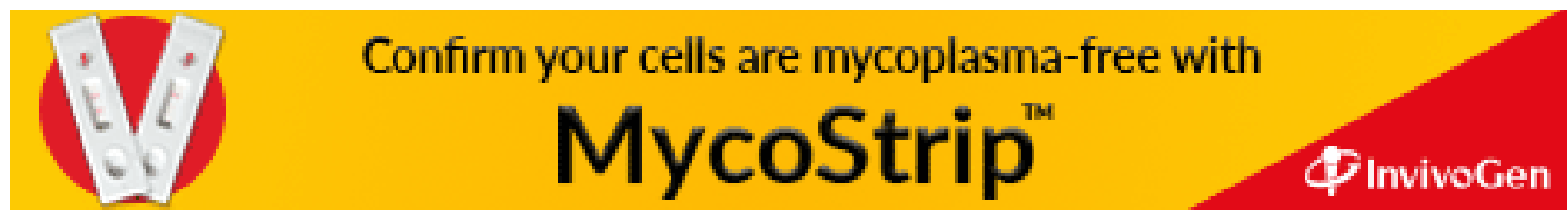

